\title{
O NASCIMENTO DA MODERNIDADE NA FRANÇA SETECENTISTA ${ }^{1}$
}

Renato Moscateli*

O homem nasceu para a ação como o fogo tende para cima e a pedra para baixo.

Não estar ocupado e não existir é a mesma coisa para o homem.

Voltaire

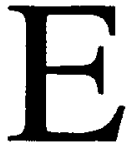

m seu brilhante livro intitulado Tiıdo o que é sólido desmancha no ar, o ensaísta americano Marshall Berman descreveu as diversas nuanças de um processo fundamental na História do Ocidente, um movimento complexo e radical que reformulou o modo de viver, as tradições e as crenças de uma forma tal como nunca havia ocorrido antes. A modernidade, esse fenômeno irresistível e devastador que atravessou os últimos cinco séculos. Berman explo-

* Mestrando em História Social pelo Programa Associado de Pós-Graduação em História Universidade Estadual de Maringá/Universidade de Londrina.

I O presente artigo é uma síntese dos resultados de uma pesquisa realizada entre 1998 e 1999 no curso de graduação de História da UEM, sob a orientação do Prof. Dr. David Ferreira de Paula. 
rou-a com a ajuda da literatura e da arquitetura das grandes cidades para iluminá-la e mostrar os diversos caminhos através dos quais ela penetrou na cultura européia e, a partir dela, em quase todo o mundo, ajudando a revolucionar constantemente a essência das sociedades que encontrou pela frente, como se fosse um turbilhão inesgotável.

A inspiração de Berman para estudar as experiências da modernidade, como o título do livro informa, foi um excerto do Manifesto Comunista de Karl Marx e Friedrich Engels, no qual os autores sintetizaram o que para eles representava a característica basilar do capitalismo, istoé, o poder de convulsionar ininterruptamente todas as coisas. Na época burguesa, dizem Marx e Engels,

todas as relações firmes, sólidas, com sua série de preconceitos e opiniōes antigas e veneráveis, foram varridas, todas as novas tornaram-se antiquadas antes que pudessem ossificar. Tudo o que é sólido desmancha no ar, tudo o que é sagrado é profanado, e o homem é, finalmente, compelido a enfrentar de modo sensato suas condições reais de vida e suas relações com seus semelhantes. (1996, p. 14)

A análise dos pais do socialismo científico refere-se, sobretudo, ao século XIX, quando o capitalismo alcançara um estágio avançado de desenvolvimento, podendo então sobrepujar as formas anteriores de produção e organização da vida material. Berman, por sua vez, acredita que, de modo semelhante ao da cconomia burguesa, a modernidade já dera seus primeiros passos ainda no século XVI. em pleno Renascimento, embora neste momento as pessoas não se dessem conta deste fato.

Elas tateiam, desesperadamente mas em estado de semicegueria, no encalço de um vocabulário adequado; têm pouco ou nenhum senso de um público ou comunidade moderna, dentro da qual seus julgamentos e esperanças pudessem ser compartilhados. (Berman, 1990, p.16)

Tal situação mudaria a partir da Revolução Francesa, cujo processo, com seus múltiplos desdobramentos, conduziu à formação de sensação de pertinência a uma época diferente das demais, de se fazer parte de um ponto de inflexão sem precedentes na História.

Como Tudo o que é sólido desmancha no ar ocupa-se primordialmente do período pós-revolucionário, o propósito do presente ensaio é investigar o que se 
poderia chamar de o nascimento da modernidade. Assim como Marshall Berman viu nas obras de Goethe, Marx, Baudelaire, Puchkin e Dostoievski a manifestação da modernidade no século XIX, desejo encontrar nos textos literários de Voltaire as evidências do surgimento das principais características da cultura moderna, realizando assim uma síntese de alguns estudos individuais que já realizados a respeito das obras do literato francês.

Uma questão sobre a qual se deve insistir logo de início é a de que a literatura voltaireana manteve relações originais em vários aspectos com a sociedade na qual e para a qual foi gerada. O último século do Antigo Regime é muito conhecido pelas convulsões revolucionárias de sua década final, mas é preciso lembrar, como fez Alexis de Tocqueville, que a obra da grande Revolução foi, sobretudo, a de acelerar e intensificar as tendências de mudança que já estavam em andamento antes dela (Tocqueville, 1982, p. 67). Neste sentido, ler Voltaire permite que se vislumbrem os movimentos estruturais e conjunturais que perpassavam as muitas instâncias da França setecentista, desde a esfera da política real até as práticas inerentes ao mundo do trabalho. Como o eixo da leitura que se enseja promover baseia-se no conceito de modernidade de Marshall Berman, as evidências que serão buscadas na análise da produção voltaireana estarão ligadas a três idéias mestras: a formação de um domínio público cosmopolita, a contestação/desintegração das tradições, e o que se poderia chamar de "profanação do sagrado".

Quanto à primeira dentre tais idéias, Berman afirma que antes da Revolução não havia um público para o qual as pessoas pudessem expor suas impressões a respeito dos fenômenos sociais dos quais elas próprias participavam. Ele está correto até certo ponto, pois, como mostra Pierre Lepape (1995), o mesmo processo que originou a figura do intelectual moderno, do qual Voltaire seria um exemplo, levou à formação da "opinião pública", uma espécie de entidade coletiva cujo posicionamento diante de determinadas questões adquiriu uma força política muito grande na França setecentista. Os escritores estavam entre os primeiros a mobilizar a "opinião pública" contra seus alvos — o poder absoluto do monarca, a intolerância religiosa, a censura intelectual, entre outros - e, embora nem sempre fossem vitoriosos, o simples fato de poderem levantar sua voz para conclamar a sociedade a tomar partido em suas disputas representa um passo fundamental na instalação da modernidade. $O$ poder feudal, baseado na vontade soberana do aristocrata, estava sendo paulatinamente substituído por práticas mais complexas de deliberação política que exigiam o reconhecimento do direito de os súditos - e mais tarde dos cidadãos - opinarem sobre o que lhes dizia respeito, até mesmo porque o âmbito do que dizia respeito às pessoas comuns crescera consideravelmente no século XVIII.

Diversos reinos da Europa ocidental também participaram, em maior ou menor medida, dessas mudanças de ordem sócio-política verificadas na França. Talvez a "opinião pública" não fosse em todos eles tão relevante quanto na terra de 
Voltaire, mas a busca de uma parte da população — uma elite — por esclarecimento e erudição como meios para adquirir uma cultura ampla e cosmopolita, capaz de vencer as particularidades de cada país e as restrições ao conhecimento impostas pelo controle oficial da informação, encontrou considerável ressonância. Durante um longo período, a fé cristã servira de ligação entre os povos europeus, por ser aquilo que eles tinham em comum apesar de todas as suas divergências. A Reforma Protestante enfraqueceu este elo, que seria novamente construído pelo Iluminismo.

Pela metade do século [XVIII], a "filosofia" era vista como o código comum que uma parte da elite intelectual e social havia adotado (...), numa adesão coletiva à Razão, à urbanidade dos costumes e à idéia de progresso. De Londres a Moscou, de Estocolmo a Lisboa, forjava-se a unidade intelectual de uma Europa de "pessoas distintas", cultas, que falavam e escreviam o francês (...), cheias de curiosidade pela ciência, adeptas de reformas, inimigas do fanatismo e da superstição. Voltaire ocupava um lugar central na elaboração deste código. (Lepape, 1995, p.147-148)

Qual era exatamente o papel do literato francês? Como escritor talentoso e incansável que era, Voltaire procurava abranger em sua produção literária todos os assuntos que pelos quais a elite das "pessoas distintas" interessava-se. Na coletânea de textos estudados neste ensaio isto fica bem claro. Fosse a crítica ao fanatismo de Cândido, fossem as investigações econômicas de $O$ homem dos quarenta escudos, fosse ainda a discussão da filosofia e da ciência neste último conto e na Aventura da memória, ou então a reflexão sobre a origem do poder secular em Senhor, Voltaire lidava com qualquer tema com a mesma desenvoltura com que escrevera os poemas satíricos de sua juventude. Talvez isto não fizesse de seus leitores um público nos moldes do que existiria no século XIX, mas ainda assim o teor e o conteúdo de tais obras ajudava a romper o relativo isolamento que havia entre as ordens sociais francesas, fazendo com que questões que permeavam a situação de uma delas fosse conhecida e discutida pelas outras.

Os casos judiciais em que Voltaire se envolveu na década de 1760 e que são descritos em $O$ homem dos quarenta escudos são uma demonstração do quanto avançara a modernidade na França ${ }^{2}$. A autoridade dos parlamentares de Toulouse já

2 Estes casos judiciais referem-se aos incidentes ligados às famílias Calas e Sirven. Jeiın Calas, um protestante que vivia em Toulouse, tinha um filho que se suicidara, provavelmente por motivo de problemas financeiros, e uma filha que se tornara católica. Como em Toulouse havia uma lei estabe. 
podia ser contestada pelas "pessoas comuns" que não mais se contentavam em permanecer à margem do governo. Mais do que uma simples reação ao que se pensava ser uma injustiça, a atitude da população em relação aos casos Calas e Sirven revela a força contida na utilização da publicidade por um mero escritor. Se conhecimento é poder, ao tornar pública uma decisão questionável de alguns juízes provincianos, Voltaire fez com que eles tivessem de justificar sua posição perante a sociedade, uma vez que esta passara a ver como de seu interesse o destino daqueles que foram condenados. Surgira, enfim, um ambiente de discussão, um espaço social de embate de idéias que era a semente da comunidade moderna de que nos fala Marshall Berman. Ao contrário do episódio ficcional em que o plebeu russo confronta um membro da aristocracia, o qual Berman afirma que somente poderia ter ocorrido após a revolução bolchevique (1990, p. 207-208), o desafio real das "pessoas comuns" ao Antigo Regime não precisou esperar por uma revolução que destituísse a nobreza. Graças a seu status no campo literário, Voltaire, um simples escritor, era capaz de vencer a censura do Estado e o sigilo do poder em nome de uma concepção moderna de ação pública.

Tudo isto indicava uma profunda quebra nas tradições que regiam a sociedade de ordens da França. Acumuladas ao longo dos anos, as tensões políticas e econômicas tornavam instáveis as estruturas do absolutismo, ameaçando a hegemonia da aristocracia. Os escritos de Voltaire estão repletos de referências a esse processo.

Em se tratando da vida econômica na França do século XVIII, a análise das obras literárias voltaireanas indicou uma grande preocupação do autor em salientar a necessidade imperiosa de se abandonar certos costumes "arcaicos" a fim de que a riqueza do reino deixasse de ser ilusória para tornar-se concreta. A crítica à fisiocracia presente em $O$ homem dos quarenta escudos nada mais é do que um apelo em favor da adequação do Estado, sobretudo de seu sistema tributário, às práticas produtivas capitalistas em desenvolvimento naquele período. Dentro do sistema feudal de ordens hierárquicas, a burguesia surgia como uma classe dinâmica em busca de um espaço maior para exercer suas atividades, o que tornava cada vez mais problemá-

lecendo a exposição e a execração pública dos cadáveres dos suicidas, Calas pedira aos amigos que testemunhassem ter sido natural a morte de seu filho. Começaram então a circular boatos de que o pai matara o filho para impedir sua conversão ao catolicismo, e o Sr. Calas acabou sendo preso, torturado e executado em 1761. Os membros remanescentes da familia pediram entāo a ajuda de Voltaire para reabilitar o nome dos Calas. Quanto ao caso Sirven, novamente as leis intolerantes foram a causa do incidente. Tendo sido revogado o Edito de Nantes, a lgreja podia requerer a guarda de filhos de casais protestantes alegando que iria convertê-los ao catolicismo. Foi o que $\propto$ correu no ano de 1764 com Élisabeth Sirven, arrancada da família e entregue ao bispo de Castres. Este, que não hesitou em usar de violência para alcançar seus objetivos, acabou enlouquecendo a moça, a qual se matou atirando-se em um poço. Acusados de assassinato, os Sirvens refugiaram-se em Ferney, de onde saíram em 1771 para se entregarem à justiça. Em ambos os litígios, a fama e a insistência de Voltaire mostraram-se mais poderosas do que a arbitrariedade do sistema judicial francês, e graças à sua interferência as duas famílias foram finalmente reabilitadas e indenizadas. 
ticas as inúmeras distinções jurídico-tributárias do Antigo Regime. O que o Geômetra do conto voltaireano exigia em nome da racionalidade nada mais era do que o fim dos costumes feudais de taxação, os quais deveriam ser substituídos pelos imperativos econômicos da participação de todos os súditos no sustento do Estado igualdade perante a lei - e da proporcionalidade de tributação de acordo com a riqueza pessoal. Uma tal proposta implicava o fim de tradições seculares de diferenciação social, pois desprezava os privilégios hereditários da nobreza e as isenções fiscais concedidas ao clero desde os primórdios da constituição do absolutismo. Neste sentido, a modernidade significa romper com os fundamentos de um mundo arcaico em que o valor de cada pessoa - e conseqüentemente sua contribuição ao governo - estava dado desde seu nascimento, para trazer à tona um novo mundo onde o papel dos indivíduos na sociedade seria definido pelo que eles mesmos fizessem. Afinal,

A idéia da modernidade, na sua forma mais ambiciosa, foi a afirmação de que o homem é o que ele faz, e que, portanto, deve existir uma correspondência cada vez mais estreita entre a produção, tornada mais eficaz pela ciência, pela tecnologia ou a administração, a organização da sociedade, regulada pela lei e a vida pessoal, animada pelo interesse, mas também pela vontade de se liberar de todas as opressōes. (Touraine, 1997, p. 9)

Essa realidade obsoleta a ser ultrapassada aparece também $\mathrm{cm} O \operatorname{lngênuo}$. onde os procedimentos personalistas da administração do reino chocam o protagonista do conto, cuja ignorância quanto aos costumes da conte não lhe permitia perceber os desdobramentos de um tipo de governo fundado sobre a pluralidade de status jurídicos como era a França das três ordens, cada qual com sua posição na hierarquia dos privilégios. Graças à influência de certos membros do clero junto ao Estado, o jovem hurão viu-se preso na Bastilha sem ao menos conhecer o motivo de sua desgraça, pois os confessores do rei e dos ministros possuíam quase tanto poder quanto seus penitentes. Naquele mundo retratado por Voltaire, a autoridade individual, manifesta através do clientelismo, ainda se sobrepunha às tentativas de se construir um governo de racionalidade burocrática.

A chamada "reação feudal" empreendida pela nobreza no século XVIII insere-se nesse contexto de confronto com a modernização, pois demonstra a resistência da aristocracia em abdicar de seu poder pessoal entregando o Estado nas mãos dos plebeus. Mesmo quando o absolutismo buscou criar mecanismos que tornassem sua estrutura menos dependente das antigas formas feudais de controle dos súditos, os nobres tentaram a todo custo manter intocada sua esfera de poder. $O$ 
estabelecimento da venalidade de cargos públicos, uma porta aberta para a burguesia desejosa de transformar sua riqueza em status, foi parcialmente neutralizado pelos aristocratas no século da Revolução, o que por um lado ia contra os objetivos dos plebeus, mas por outro, correspondia, na visão de Voltaire, a um progresso, caso isso fizesse com que o Estado fosse dirigido por aqueles que tinham o mérito necessário, e não o dinheiro suficiente para tanto. A alegórica visita do profeta Babuc à cidade de Persépolis em $O$ mundo como está é reveladora a esse respeito. Quando informam Babuc que entre os persas punham em leilão as dignidades da paz e da guerra, ele soube que seria desnecessária a fúria divina, da qual era emissário, para destruir um povo tão ávido de riquezas e tão pouco responsável em gerila. A lamentação do Sr. de Marsais em Pot-Pourri expressa o mesmo sentimento de revolta diante desse costume que beneficiava uns poucos enquanto relegava ao esquecimento tantos indivíduos capazes.

A transformação cultural, que seria inevitavelmente necessária antes que cada homem pudesse apelar apenas a seu talento caso desejasse ascender socialmente, estava também ligada à luta contra a influência do cristianismo na visão de mundo do povo francês. De fato, para Voltaire, não somente a ingerência direta da Igreja na economia, como inclusive o impacto da religião no cotidiano das classes populares merecia reprovação. Em Pot-Pourri, o exemplo dos trabalhadores que preferem o ócio dos feriados católicos à rotina da produção é comparável àquele dos camponeses mencionados em $O$ homem dos quarenta escudos, cujo desejo é o de abandonar a vida laboriosa de seus pais para se tornarem membros do clero. Nos dois casos, a ação criadora vê-se preterida em favor da inércia do ofício eclesiástico, e a fonte da modernidade, o fazer produtivo, esbarra na mentalidade reacionária de uma sociedade governada pelos códigos da nobreza e da Igreja. Como Berman mostra, a luta pelo progresso empreendida pelo Fausto de Goethe enfrenta os mesmos desafios que os vislumbrados por Voltaire, ou seja, a persistência de hábitos seculares que cerceiam a livre expressão do trabalho transformador. $\mathrm{O}$ que Fausto deseja é "agir de maneira efetiva contra o mundo feudal e patriarcal: para conseguir um ambiente social radicalmente novo, destinado a esvaziar de vez o velho mundo ou destruí-lo" (Berman, 1990, p. 61). Talvez o projeto voltaireano não seja tão revolucionário quanto o de Fausto, mas é um mesmo espírito que os anima: ambos pretendem canalizar os esforços humanos em benefício da comunidade, ainda que para isto seja preciso profanar as crenças mais sagradas que norteiam a vida de seus membros. O catolicismo, com sua infinidade de dogmas e preceitos, tinha de ceder ante o avanço inexorável dos valores burgueses, dos quais Voltaire se faz arauto.

A apologia da atividade criadora, esse marco distintivo da modernidade, reveste-se também de uma roupagem inesperada em $O$ homem dos quarenta escudos. A Igreja já fora então condenada por custar caro aos cofres públicos, e o Geômetra encontra nela uma outra mácula a ser apagada: o celibato. Para ele, o fato de o clero privar o governo de recursos monetários não era seu único "pecado": ao 
impedir, através do celibato, a geração de novos súditos, a Igreja reprimia uma importantíssima fonte de renovação social, de rejuvenescimento da comunidade. Os monges são descritos por Voltaire como cadáveres, e seus claustros, como túmulos. Isto contrariava a racionalidade das "Luzes", pois, ao invés de isolamento espiritual, o que a modernidade iluminista exige é a praxis, o engajamento pela ação, a ressurreição desses homens e mulheres mediante o trabalho:

Quanto mais se multiplicam as artes, mais necessário é o número de súditos laboriosos. Há sem dúvida pelos claustros muitas inteligências sepultas, que estão perdidas para o Estado. É preciso, para que um reino floresça, o mínimo possível de padres e o máximo possível de artesãos. (Voltaire, 1972, p. 393)

Embora a França fosse então um dos países mais populosos da Europa, Voltaire pensava que quanto maior fosse o alcance do monaquismo, maiores seriam os prejuízos em termos de recursos humanos para a monarquia dos Luíses.

Essa visão materialista do papel do clero na sociedade contrastava profundamente com as formas costumeiras de pensar a função da Igreja num reino católico. "Profanando" a imagem sagrada dos clérigos - como diria Marx -, Voltaire desnudou de sua auréola uma ocupação até então honrada e admirada com respeito reverente. De fato, ao tratar os religiosos como quaisquer outros individuos, o escritor reduzia a importância dos mesmos, igualava ao comum o que deveria ser superior, posto que mais próximo da divindade. O caráter moderno da luta voltaireana contra a supremacia ideológica da Igreja evidencia-se nos texto literários que tocam na questão da intolerância religiosa, onde esta é considerada não em seus aspectos puramente morais ou teológicos, mas em termos de seus impactos na vida material. A revogação do Edito de Nantes, em 1685, reacendera o ódio aos protestantes, e Voltaire mostra, tanto em $O$ homem dos quarenta escudos como em $O$ Ingênuo, que o Estado francês, em nome desse ódio, perdera centenas de milhares de súditos somente para agradar o papa. Segundo o autor, tal perda refletia-se de modo negativo no mercado de trabalho, criando um vácuo de mão-de-obra capaz de intensificar a crise econômica que assolou o reino em todo o século XVIII. Como exemplo a ser seguido pela França, a Holanda aparece em Pot-Pourri como uma terra marcada pela diversidade religiosa e ao mesmo tempo pela prosperidade material, duas circunstâncias permitidas pela liberdade de culto que não existia na pátria de Voltaire e que tantos problemas poderia solucionar.

Da mesma maneira como identifica na ação da Igreja seus componentes econômicos, Voltaire percebe e denuncia os interesses políticos do clero. A célebre viagem do protagonista de Cândido ao Paraguai dá o tom de uma crítica mordaz ao 
modo como os membros da Companhia de Jesus imiscuíam-se nos negócios do Estado para até mesmo suplantá-lo em certos momentos. Os jesuítas dirigiam boa parte do ensino e da divulgação da informação na França, controlando, portanto, áreas estratégicas da sociedade. Ainda que os eventos que juntaram Cândido e os jesuítas ocorram na América, o contexto de interferência dos religiosos na vida secular é o mesmo da França setecentista: na literatura e na história, os eclesiásticos ocupavam um lugar privilegiado na hierarquia política, o que Voltaire combatia em função de sua visão de mundo burguesa e anticlerical. Na modernidade prefigurada na obra do escritor, a política deveria ocorrer longe do âmbito da religião; ela tinha de ser despida de qualquer tipo de recurso à fé ou à credulidade do povo comum, para poder ser reconstruída sobre os alicerces da racionalidade.

Os primeiros passos em direção a esse modelo moderno de autoridade já haviam sido dados no tempo de Voltaire, e ele mesmo contribuiu para isto. A fábula contida no verbete Senhor do Dicionário Filosófico demonstra que a "ideologia" legitimadora da monarquia absolutista, a teoria do direito divino, estava em plena fase de contestação no século XVIII. Em oposição aos discursos como o de Bossuet, que defendia a origem sobre-humana do poder real, Voltaire expôs uma nova concepção de política que nada devia à teologia ou à religião. Na fábula, é a violência que serve de princípio fundador do dominio de um homem sobre seus semelhantes. Quanto à crença no sobrenatural, Voltaire referiu-se a ela como sendo uma invenção do tirano para consolidar a submissão de seus governados, apenas mais um mito que as leis e os costumes perpetuaram. Como afirmam Adorno e Horkheimer, "no mundo do iluminismo, a mitologia entrou na esfera do profano" (1996, p. 45). Com isto, o literato desmistificou a fonte da autoridade do monarca, contribuindo para enfraquecê-la da mesma forma como o próprio desenvolvimento dialético do Estado absolutista estava fazendo ${ }^{3}$ (Rémond, 1976, p. 75).

Outra origem de questionamento do poder monárquico encontrava-se nos parlamentos. Pouco lembrados por pesquisadores que simplificam a imagem da estrutura governamental francesa, os parlamentos provinciais e de Paris constituíam focos de resistência ao arbítrio real, algo lembrado por Voltaire em seu Elogio

3 Em seu ensaio a respeito da relaçāo entre imagens e objetos na história da filosofia, Olgária C. F. Matos mostra como a racionalidade das Luzes ataca o caráter "sagrado" da natureza, demitizando e "desenfeitiçando" o universo. Onde antes existia o mito como centro, como referencial para a vida, o Iluminismo coloca a razão: "A modernidade iluminista elimina o ponto de referência da 'pessoa' mítica, aquela que vive no ciclo natural" (Matos, 1993, p. 75). Em se tratando da monarquia de "direito divino", os discursos dos philosophes buscam justamente destruí-la como marco para a esfera política, demonstrando, através da análise racional da mesma, que ela não pode ser o fundamento do poder, posto que se sustenta em um engodo. Assim, a autoridade "natural" do rei, aquela que, acreditava-se, fora-the delegada pelo próprio Deus e que unia a vida do monarca ao ciclo da natureza presente em seus domínios, perde sua justificativa, devendo encontrar um novo tipo de legitimidade baseada na funcionalidade e na eficiência. 
histórico da Razão. Os magistrados deste conto faziam coro com o povo que exigia mudanças de ordem política, uma vez que, na qualidade de guardiões das leis, eles deviam opor-se ao governante sempre que este ultrapassasse os limites de sua função. É bastante significativo que Voltaire preencha seus textos com conflitos dessa natureza, iluminando assim com suas palavras certas contradições administrativas que poderiam passar despercebidas em uma observação superficial da "toda poderosa" monarquia absoluta. A presença do povo nessa obra de Voltaire é ainda mais importante, uma vez que chama a atenção para um fato fundamental na história da modernidade: a entrada das "pessoas comuns", como coletividade, na esfera política. A inserção de vinte milhões de personagens anônimos no conto, de uma multidão de franceses desejosos de mudanças no reino, informa-nos da força que os membros do Terceiro Estado adquiriram no século XVIII, especialmente como parte da incipiente "opinião pública".

As representações de um rei sem autoridade sobrenatural e de um clero comprometido demais com questões mundanas, ambas mesclas profanas entre o infinito e o limitado (Voltaire, 1972, p. 655), não são as únicas construídas por Voltaire a respeito da elite dirigente de sua época. Em Jeannot $e$ Colin, o autor pinta um interessante retrato da aristocracia que habitava a célebre corte francesa. Quando os novos-ricos Jeannotière ingressam na nobreza, a educação que desejam dar a seu filho, o futuro marquês, mostra-se totalmente inútil diante do tipo de vida ociosa que lhe caberia no futuro. Aqueles aristocratas que detinham riquezas e poder, afirma o conto voltaireano, jamais se preocupavam com qualquer conhecimento prático, visto que toda a atividade produtiva era-lhes vedada, e assim permaneciam em um luxuoso estado de ignorância (Voltaire, 1972, p. 270-272). Porém, tão rápido quanto enriqueceram, os Jeannotière perderam sua fortuna, e os eventos da história levaram-nos a concluir que apenas a vida laboriosa é um porto seguro. Ora, tal elogio ao trabalho demarca nitidamente as diretrizes da modernidade na obra voltaireana. Não se trata apenas de uma crítica à frivolidade da nobreza, ou de um apelo conservador à permanência dos camponeses em suas atividades tradicionais. Em Jeannot e Colin, Voltaire contrapõe as figuras decadentes da nobreza, estáticas e reacionárias, ao dinamismo dos pequenos burgueses. A oposição de classes é clara, mas não resume tudo. Para além dela, há a afirmação de que o fazer produtivo dos trabalhadores é superior ao luxo estéril dos governantes. Ao invés de permanecer naquele mundo de prazeres ilusórios da corte, ficando preso ao aprendizado da indolência, Jeannot teve de voltar ao mundo do trabalho para encontrar a verdadeira felicidade.

Em Cândido, o protagonista percorreu igual caminho rumo ao reconhe-cimento de que a realização pessoal estava na ação criadora. Nascido em meio à nobreza, Cândido foi expulso do pacato castelo de Thunder-ten-tronckh, onde "tudo estava bem", para partir em sua busca pelo "melhor dos mundos possíveis" do qual 
lhe falara o mestre Pangloss. A aparentemente interminável viagem de Cândido pelo mundo colocou-o em contato com as mais diferentes culturas, com os mais estranhos tipos humanos existentes, e em lugar algum ele deparou-se com bemaventurança definitiva. Mesmo no Eldorado, a terra sem cobiça em que todos viviam com fartura, ele não pôde permanecer, pois ficar ali seria "imobilizar-se e morrer" (Fachin, 1995, p. 123): o retorno à Europa significava a volta à ação. Todo o complexo de experiências adquiridas por Cândido em sua jornada levou-o a enfrentar o fato de que o "melhor dos mundos possíveis" não existe, mas que a vida pode adquirir um novo sentido através do trabalho. Esta solução burguesa, como diria Lídia Fachin, na verdade é a resposta da modernidade à crise do universo feudal. Contra o imobilismo da aristocracia, contra as tradições seculares da religião, contra, enfim, o conformismo da filosofia leibniziana, Cândido valoriza o papel do ser humano como transformador de suas condições de vida e construtor de sua história. Nada poderia ser mais moderno do que isto.

Olhando para o conjunto dos textos de Voltaire analisados nesta pesquisa, vê-se que a presença da modernidade é bem mais freqüente do que uma leitura superficial apontaria. Isto não quer dizer que todas as características desse fenômeno revolucionário encontrem-se plenamente configuradas nas obras do escritor, o que somente seria possível caso Voltaire não fosse, ainda, um homem do Antigo Regime. Na maior parte do tempo, aquilo que o século XIX experimentaria como elementos cotidianos modernos, Voltaire apenas indica como sendo anseios de sua própria época. Entretanto, aqueles princípios básicos da modernidade salientados por Berman na obras de Goethe e Marx são os mesmo que tornam os escritos voltaireanos documentos valiosos para o conhecimento do contexto em que foram produzidos e também, por que não, dos tempos que lhe sucederiam. A ânsia por destruir tudo o que fosse tradicional e arcaico, o desejo de retirar o "véu sagrado" que ocultava as relações entre os homens, a impaciência pela chegada de um novo mundo guiado pelo impulso criativo, tudo isto está em Voltaire, fosse porque ele era um burguês cansado de permanecer fechado dentro das muralhas do feudalismo, fosse porque ele era um artista cuja produção exigia um público maior do que as fronteiras sociais do Antigo Regime poderiam permitir, fosse ainda porque ele era um homem para quem a necessidade de ação era imperiosa, para quem "não estar ocupado e não existir vêm a dar na mesma coisa".

A energia criadora de Voltaire é a síntese pessoal das forças sociais que a modernidade estava começando a liberar no século XVIII. Tudo o que havia de sólido no reino dos três Estados principiara a ser abalado, e a profanação do sagrado poder da Igreja realizada pelo Iluminismo já havia feito substanciais progressos. Junto ao avanço da burguesia, os escritos de Voltaire objetivavam fazer com que os homens enfrentassem de modo sensato suas reais condições de vida e suas relações com seus semelhantes, constituindo obras que revelam o sentido revolucionário que a História tomava no momento em que foram enunciadas. A literatura voltaireana, 
enfim, impregnou-se da modernidade que nascia na França setecentista, e embora o Antigo Regime tenha sobrevivido alguns anos após a morte de Voltaire, os novos valores contidos nos textos do literato permaneceriam por muito mais tempo do que a monarquia dos Luíses poderia desejar.

\section{RESUMO}

O presente artigo discute a possibilidade de se vislumbrar as características da modernidade no interior das obras literárias de François-Marie Arouet, o escritor conhecido como Voltaire. Tendo como inspiração o trabalho do ensaísta americano Marshall Berman, o texto baseia-se em três idéias fundamentais para se compreender a modernidade, as quais são utilizadas como fio condutor para a análise das obras voltaireanas: a formação de um domínio público cosmopolita, a contestação/desintegração das tradições, e o que se poderia chamar de "profanação do sagrado".

Palavras-chave: Voltaire, França, modernidade.

\section{ABSTRACT}

The present article discusses the possibility to meet the characteristics of the modernity inside the literary works of François-Marie Arouet, the well-known writer like Voltaire. Being inspired by the American essayist's Marshall Berman work, the text is based on three fundamental ideas to understand the modernity, which are used as thread-driver for the analysis of the works of Voltaire: the formation of a cosmopolitan public domain, the critic/disintegration of the traditions, and something that one could call "profanation of the sacred".

Key words: Voltaire, France, modernity.

\section{REFERÊNCIAS}

ADORNO, T. W., HORKHEIMER, M. Conceito de iluminismo. In: Adorno. Trad. Zeljko Loparic et al. São Paulo: Nova Cultural, 1996. p. 15-62. (Os pensadores)

BERMAN, Marshall. Tudo o que é sólido desmancha no ar. Trad. Carlos F. Moisés e Ana Maria L. Ioriatti. São Paulo: Cia. das Letras, 1990. 
MOSCATELI, Renato O nascimento da modernidade...

FACHIN, Lídia. Polifonia, carnavalização e paródia em "Candide" de Voltaire. Revista de Letras, São Paulo, v. 35, p. 113-125, 1995.

LEPAPE, Pierre. Voltaire: Nascimento dos intelectuais no Século das Luzes. Trad. Mário Pontes. Rio de Janeiro: Zahar, 1995.

MARX, Karl, ENGELS, Friedrich. O manifesto do partido comunista. Trad. Maria L. Como. Rio de Janeiro: Paz e Terra, 1996.

MATOS, Olgária C. F. O iluminismo visionário: Benjamin, leitor de Descartes e Kant. São Paulo: Brasiliense, 1993.

RÉMOND, René. O Antigo Regime e a Revolução. Trad. Frederico de Barros e Octavio M. Cajado. São Paulo: Cultrix, 1976.

TOCQUEVILLE, Alexis de. O Antigo Regime e a Revolução. 2. ed. Brasília: Universidade de Brasília, 1979.

TOURAINE, Alain. Crítica da modernidade. 4. ed. Trad. Elia F. Edel. Petrópolis: Vozes, 1997.

VOLTAIRE (François Marie Arouet). Contos. Trad. Mário Quintana. São Paulo: Abril Cultural, 1972.

. Dicionário Filosófico. In: Voltaire v. l, Diderot. São Paulo: Nova Cultural, 1988. p. 1-211. (Os Pensadores) 